\title{
Patient Portals as a Means of Information and Communication Technology Support to Patient- Centric Care Coordination - the Missing Evidence and the Challenges of Evaluation
}

\section{A joint contribution of IMIA WG EVAL and EFMI WG EVAL}

\author{
Michael Rigby' ${ }^{1}$ Andrew Georgiou' ${ }^{2}$ Hannele Hyppönen ${ }^{3}$, Elske Ammenwerth ${ }^{4}$, Nicolette de \\ Keizer ${ }^{5}$, Farah Magrabi ${ }^{2}$, Philip Scott ${ }^{6}$ \\ 1 Keele University, School of Public Policy and Professional Practice, Keele, United Kingdom \\ 2 Australian Institute of Health Innovation, Macquarie University, Sydney, Australia \\ ${ }^{3}$ National Institute for Health and Welfare, Information Department, Helsinki, Finland \\ 4 UMIT, University for Health Sciences, Medical Informatics and Technology, Hall in Tyrol, Austria \\ ${ }^{5}$ Academic Medical Center, Department of Medical Informatics, Amsterdam, The Netherlands \\ 6 School of Computing, University of Portsmouth, Portsmouth, United Kingdom
}

\begin{abstract}
Summary
Objectives: To review the potential contribution of Information and Communication Technology (ICT) to enable patient-centric and coordinated care, and in particular to explore the role of patient portals as a developing ICT tool, to assess the available evidence, and to describe the evaluation challenges.

Methods: Reviews of IMIA, EFMI, and other initiatives, together with literature reviews.

Results: We present the progression from care coordination to care integration, and from patient-centric to person-centric approaches. We describe the different roles of ICT as an enabler of the effective presentation of information as and when needed. We focus on the patient's role as a co-producer of health as well as the focus and purpose of care. We discuss the need for changing organisational processes as well as the current mixed evidence regarding patient portals as a logical tool, and the reasons for this dichotomy, together with the evaluation principles supported by theoretical frameworks so as to yield robust evidence.

Conclusions: There is expressed commitment to coordinated care and to putting the patient in the centre. However to achieve this, new interactive patient portals will be needed to enable peer communication by all stakeholders induding patients and professionals. Few portals capable of this exist to date. The evaluation of these portals as enablers of system change, rather than as simple windows into electronic records, is at an early stage and novel evaluation approaches are needed.
\end{abstract}

\section{Keywords}

Patient-centred care, care coordination, patient portals, evidence, evaluation

Yearb Med Inform 2015;10:148-59

http://dx.doi.org/10.15265//Y-2015-007

Published online June 30, 2015

\section{Understanding Person-centred} Care and Care Coordination

\section{What are Patient-centred Care and} Person-centred Care?

While Patient-centred care is the subject of much consideration, it still puts the citizen with health needs in a subordinate relationship as the "patient". By contrast, Person-centred care recognises the patient's full autonomy as a person in society who happens to need health-related services, and moves away from a hierarchical relationship. The Person-centred health system has recently been defined as one that "supports people to make informed decisions and to successfully manage their own health and care and to invite others to act on their behalf ... Person-centred care sees patients as equal partners in planning, developing and assessing care" [1]. Or put more succinctly, Person-centred care is personalised, coordinated, and enabling, and the person is treated with dignity, compassion and respect [2]. It also goes beyond simply linking individual components of treatment or care by integrating them into one holistic package with shared responsibility for delivery to an agreed pattern [3-5]. Although Person-centred care is a more encompassing and richer concept than
Patient-centred care, there is surprisingly little empirical literature on either $[6,7]$; this despite the fact that it was the standard set by Hippocrates [8-10].

The advent of Patient Portals, whereby the patient may access his/her medical or health record, would seem to offer an important contribution to improving the patient-practitioner knowledge balance, and to make the patient fully aware of the facts related to his/her condition and treatment. In turn, this would appear to empower the patient as a participant in the negotiation of his/her own care to ensure that it is integrated and fits his/ her preferences wherever possible. However, we find that the evidence of this effect is worryingly sparse, due in particular to the lack of effective evaluation of patient portals.

In general in this paper, we use the term "patient" as representing the common current approach to recipients of health services, recognising that neither "person" in this context, nor "care recipient", are yet in common use though they might be considered more appropriate. The term "consumer" is used when underpinning the real relationship which should prevail, and "citizen" when underscoring that recipients should be indistinguishable as integrated members of the community, and indeed may be concurrently both patients and informal carers of others. 


\section{What is Care Coordination?}

According to the Care Coordination Measures Atlas, "Care coordination is the deliberate organization of patient care activities between two or more participants (including the patient) involved in a patient's care to facilitate the appropriate delivery of health care services. Organizing care involves the marshalling of personnel and other resources needed to carry out all required patient care activities and is often managed by the exchange of information among participants responsible for different aspects of care" [11]. Concepts of "Care coordination", "Patient-centred care", and "Person-centred care" are to a large extent used in relation to the management of chronic diseases, which generate specific patient care needs and challenges for health services [12]. Care coordination necessitates an array of different actors and actions becoming aligned for prevention, early detection, and management of chronic illnesses. The interests and wishes of patients, who find person-centric coordinated care more personal and satisfactory, are coming to the fore at a time when health systems with increasingly stretched resources need to ensure that a growing population of patients with chronic diseases receives the best treatment regimens to control disease and mitigate symptoms [12]. Both approaches have a common interest in the good information and support needed to facilitate self-management of health. According to the WHO, governments too have a crucial role to play in improving the health and well being of populations, and in providing special protection for vulnerable groups [13].

The most successful interventions for patient-centred management and coordination of care are often the most complex, requiring a change of care practices as well as the implementation of new tools. These changes include increasing clinical expertise and decision support; improving patients' self-management motivation and skills; increasing the effectiveness of practice teams and their interactions with patients; and having more accessible and useful clinical information $[12,14,15]$.

Central to this reframing of care are three concepts - i) professional providers' re-orientation to involve the patient (acute patient or chronic disease sufferer) in his/her care and trajectory; ii) active management of aspects of his/her condition by the patient; and iii) shared information about needs and actions by all parties. Selection and targeting of interventions require information on the needs of those with chronic diseases, and some countries have monitored citizens' and professionals' current use and benefits of existing information and tools for chronic care prevention, risk detection, and management [16-19].

\section{The Patient's Role in his/her own Well-being and Care}

The sharing of responsibility between diagnosed patients and providers, leading to improved coordination and integration of care, is not a new idea [20,21]. For those patients with chronic or enduring conditions, there has been recognition of the expertise they build up about the condition which they have permanently, but which the clinician sees only occasionally, such that the concept of the "Expert Patient" was coined more than a decade ago, accompanied by a related policy programme [22], which still endures in English NHS policy [23, 24]. There is a strong belief that many of today's patients are increasingly in search of more information about their health and are keen to establish a closer engagement with medical providers about the way their care is undertaken and managed [21]. Research evidence consistently shows that patients want to be kept involved and regularly informed about decisions related to their medical care [25]. Legal system decisions have continued to support these principles by upholding the right of patients to receive timely information about medical tests [26].

This is also at a time when consumerism and consumer orientation are increasing significantly. For most upper- and middle-income countries, on-line consumer access to information is readily available. Many citizens are fluent in on-line services such as retail purchasing and travel booking, and see this not just as time saving, but as a means of determining the specific service configuration of their choice. Such on-line services are increasingly sophisticated, for instance the civil aviation sector has progressed from simple on-line bookings to on-line check-in, seat selection, meal choice, and choice of additional services. In all these cases, the consumer accesses and manages his/her own data, even within a complex and safety critical corporate system.

Similarly, in the health context, patient information needs should not be limited to obtaining general knowledge. There should be opportunity for patients to access their medical records and the content within them. Providing patients with access to personalized health information is believed to be a means of improving communication between patients and providers, contributing to more accurate information, and helping patients to prepare for upcoming clinical visits, and cope with the potential anxiety [27]. This notion has been supported by evidence that shows that the failure to fully inform patients can lead to poor treatment adherence [28].

Nevertheless, shared decision-making or patient-centred care is not practiced widely in many jurisdictions. According to Alston [29], part of the reason for this is the existence of major differences between what clinicians think patients should know, what patients want to know, what patients think they know, and what patients actually know. Inability to find or organise a common platform may have been a reason in the past, but due to technical advances as described from other sectors this no longer holds as a valid barrier.

\section{ICT Solutions to Support Coordination of Patient- centred Care}

\section{The Potential Roles of ICT Support}

With its core ability to enable storage and controlled sharing of the information held in electronic form, ICT support in health has a tremendous potential to facilitate the processes of Care Coordination. The ICT domain in health has worked from an early stage to this end, as fast as technological developments would allow, starting with 
institutional shared records, secure messaging, structured messages, remote read-only access, and the like. With the advent of secure communications, and of common identifiers and other reliable forms of record linkage, much richer sharing through data linkage became possible, leading over 15 years ago to the possibility of shared secure distributed records to coordinate specialist treatment care [30].

The new opportunity, given more powerful machines and consumer devices, secure communications and greater broadband bandwidth, is consumer portals. Such consumer portals, their implications and their requirements for effectiveness, based on evidence from evaluation, are the focus of this paper. At their very simplest, these are simply a window by which the patient may access his/her record as currently held, which had already been done with paper records by some innovative primary care doctors as far back as the 1980s [31]. With the advent of electronic records, some pioneers continued to promote this principle [32-34], and indeed have established both a Patient Access to Electronic Records (PAER) pressure group and a small company to provide interface software [35]. However, these pioneers have focussed solely on access to existing electronic records, establishing a key principle but not looking to change other processes, or to progress to potential integrational functions of ICT.

\section{Patient Portals - Their Nature and Function}

Patient portals are an important technological means to support patient-centred care. They are typically web-based applications that are owned and administered by a health care institution [36]. Patient portals primarily allow access to all or part of the institution's electronic medical record (EMR) data. In addition, more developed patient portals may offer advanced communication functions and services that are targeted towards enhancing medical treatment. Overall, patient portals may offer one or more of the following functionalities [37]:

- Access to EMR data of the patient

- Access to test results
- Printing or export of the portal data

- Medication refills

- Appointment scheduling

- Ability to obtain referrals

- Access to general medical information such as guidelines

- Secure messaging between the patient and the institution

Portals support the plea of the United States Institute of Medicine to give patients "unfettered access to their own medical information" [38].

Patients have regularly expressed interest in being involved in medical decision-making and in being notified of their test results, whether they are normal or abnormal [39]. It has been argued that sharing information and engaging patients to take responsibility for follow-up lead to improvements in the efficiency and effectiveness of the laboratory test process (e.g. decrease test redundancy) [40].

\section{Patient Portals as the Emergent Enablers of Understanding}

However, advanced patient portals are still a very new and innovative ICT application, whose impact on health care delivery, outcomes, and patient engagement is neither very well known nor understood $[21,41]$. Further, there are major obstacles which hinder the involvement of patients. These include a lack of access to clinical information and a lack of appropriate tools, educational aids and decision support aids that can help them to understand and engage in their own care [39]. For this reason, the development of person-centred care will need to be informed by evidence about what enhances or blocks patient engagement and involvement, along with research about the effect on patient outcomes [42]. The technological support itself is not the producer of coordinated care, but solely an enabler. The essential core activity is interaction between people - the patient, formal care providers, family, and informal carers - and each of these groups must also inter-communicate, especially within the health domain, and between health and social care. The effective patient portal is not an on-line peephole into the clinical view of the patient, but needs to be a portal for two-way and multi-party dialogue.

Of course, there are also more technical challenges to be overcome if ICT support to care coordination, especially through integrational portals, is to be achieved. These challenges include inter-operability, semantic inter-operability (including crossgroup terminologies), and controlled access within new paradigms of trust and security. However, the momentum to tackle these problems is impeded if there is no common vision of the nature of patient portals, or robust evidence to show their benefits and their optimal design.

\section{Personal Health Records}

Another, rather different, means of involving patients is the personal health record (PHRs). PHRs are "a set of computer-based tools that allow people to access and coordinate their lifelong health information and make appropriate parts of it available to those who need it" [43]. PHRs allow the patient to document health-related information and to make it available to others, for example to their health care providers or families [44]. PHRs are typically owned and administered by the patients themselves. Microsoft's HealthVault is one platform which can be used to maintain a PHR [45]. It also offers connectivity to devices and apps to enhance tracking of health information. The Apple Health app is yet another platform that can be used as a central repository to aggregate information from other health apps [46].

\section{Examples of Patient Portals}

This section examines some examples of patient portals and their typical use models, over and above the simple (but important) primary care electronic medical record access described earlier.

- At the Beth Israel Deaconess Medical Centre in Boston, USA, the medical record including clinical notes, is available via PatientSite, a web-based patient portal that offers a view of the institution's in-house EMR [47]. This portal has evolved over 13 years with over 64,000 
patients currently accessing their records including a problem list, medications, allergies, visits, and pathology and radiology test reports. Clinical notes from all departments of medicine were made available via the OpenNotes initiative which began in August 2013. Information about medications, allergies, and problems can be uploaded to Microsoft HealthVault. As in the other major health systems or academic medical centres in the USA, the use model is centred around a suite of facilities which allow patients to contact clinicians via secure email, renew prescriptions for medications, book appointments, and obtain referrals to other clinicians and services.

- Another example of an institutional portal is in Kaiser Permanente, where registrations to the patient portal began to increase in 2006, when My Health Manager (the PHR functionality, including online test results and e-mailing the doctor's office) became widely available to the members. In 2013, over $40 \%$ of Kaiser Permanente's 9 million members were reported to be registered with My Health Manager [48].

Outside the USA, the use model for consumers is generally centred exclusively on providing access to EMR data. With the exception of Finland (see below), more useful functionalities like the booking of appointments or requests for repeat prescriptions are not widely available.

- The Danish e-Health Portal, for example, currently represents the only implementation where clinical information is shared with patients on a national scale [49]. All medications, allergy information, diagnoses, laboratory test results, and discharge summaries are shared between clinicians at public hospitals, general practitioners and private specialists nationally [50]. In 2013 , over $40 \%$ of Danish citizens were reported to be accessing their health information online. But results of initial evaluations were not favourable and appear to be similar to England's summary record, the failure of which is well documented [51].

- In Australia, a Personally Controlled Electronic Health Record was imple- mented nationally in 2012 to facilitate the exchange of health information including health summaries, discharge summaries, referrals, and specialist letters [52]. The system provides a facility to view patient claims for health services and pharmaceuticals, immunisation records, and the national organ donor register. Patients are able to maintain personal health summaries, emergency contact information, and advance care directives. Like many other national implementations, this system has been plagued with problems. After two years and more than AUS \$1 billion in costs, only 1.7 million Australians had signed up to the system, and only a small subset of documents uploaded to the system were deemed to be clinically useful [53].

- In the English portal called HealthSpace, a summary of medicines, allergies, and adverse reactions was shared across the English NHS and was accessible to patients [54]. A basic account on this system enabled patients to record key personal data (e.g. blood pressure, weight) and an advanced account provided access to their summary care record and allowed them to make hospital appointments. A secure email facility was introduced but the HealthSpace system was subsequently shutdown in 2012 due to poor uptake. Current efforts in the UK are focussed on giving patients access to their GP record [55]. Primary care patient access to book appointments and request repeat prescriptions is increasingly common, though uptake remains limited even in pioneering practices [56].

- A second example of a regional system in a federal country is in Lombardy, northern Italy. Here the lifelong record is a PHR embedded into the regional universal health care information system, which now has $100 \%$ coverage of citizens and claims rapidly increasing usage [57].

In Finland, there is an ambitious E-health and E-care Strategy to develop national patient portal functionalities.

- Currently patient portals are still mainly local, maintained by municipalities, and comprise various functionalities. Additional national level access for citizens to view their patient data is rapidly increasing, and prescription data is already comprehensively available for patients on a national level. National level services (including risk test-based access to services, national service directory and feedback services) are being developed under the Ministry of Finance Action Programme on eServices and eDemocracy by the end of 2015, aligning with the new eHealth strategy. In early 2014, a national level survey was conducted evaluating citizens' usage and experiences of patient portals, and their functionalities prior to uptake of new services. Key functionalities used on the population level were information on health and illnesses, service directory, appointment booking, and viewing of prescriptions. Respondents estimated that the use of the portal functionalities had saved them on average 1.4 visits or phone calls with service providers per year. User experiences were mainly positive. The biggest obstacles included a belief that electronic communication cannot replace a personal visit, unclear terms of use, and inaccessibility of electronic services [19]. What is important for care coordination, those with a chronic illness used electronic services less than others. They experienced more frequently that the services they required were not available (monitoring own measurements, review and renewal of prescriptions, access to test results, safe communication with carers). Some of these will be available via the National system within a couple of years, some are stated in the new eHealth strategy as functionalities to be implemented by 2020 [58].

More disease-specific portals have been found to be more successful in supporting care coordination within current delivery systems.

- RenalPatientView is a patient portal offered by most UK renal units that gives patients with chronic kidney disease access to test results and information about their condition and treatment [59]. This portal shows high rates of sustained adoption by patients and (anecdotally) has resulted in improved patient safety through quicker, patient-initiated, clin- 
ical responses to abnormal test results [60]. However, in common with many similar efforts, RenalPatientView has suffered from the digital divide: sustained adoption is in inverse relation to patient deprivation score [61].

In other countries such as Singapore, Hong Kong, and Canada, access to shared EMR data is currently restricted to clinicians, with plans to make them available to patients in the future. A recent European survey showed that overall, only few European countries have established national patient portals, and that in general their uptake by the population remains low [62].

In summary, patient portals provide an interesting approach to engage patients in their own care and increase empowerment. The following use models seem to be available in various combinations:

- Institution-centred portal versus national portal

- Addressing the general population, or used by specific patient sub-groups (e.g. disease-specific)

- Only providing access to EMR data versus also offering advanced communication functions

- Read-only portal access versus also PHR functions (patients being able to add data)

- Opt-in (patients volunteer to participate) versus opt-out (patients can decide not to participate).

\section{Evidence Related to Patient Portals}

The evidence of electronic patient portals and their impact on the safety, effectiveness, and quality of patient care is limited and inconclusive $[36,63,64]$. The review by Ammenwerth et al. of the impact of electronic patient portals focussed on controlled experimental and non-experimental trials published between 1990 and 2011. The review identified four distinct studies but found no statistically significant impact on health outcomes. Significant changes were identified for office visit rates, adherence to treatment, and changes in medication regimen. The authors concluded that there is currently insufficient evidence to support the claim that patient portals empower patients and improved the quality of care. [36]

In 2013, a systematic review by Goldzweig et al. investigated the evidence about patient portals tethered to a provider electronic health record [65]. The authors identified 14 randomised controlled trials, 26 observational hypothesis-testing studies and quantitative studies, and 6 qualitative studies, and concluded that although patient attitudes are mostly positive, there is insufficient evidence to show that patient portals impact positively on health outcomes, cost or utilisation. The authors also identified disparities in portal accessibility and usability, with population groups that are ill-prepared to take on personal health record systems. The authors concluded with a strong recommendation for policy efforts to overcome racial, ethnic, and literacy barriers to portal use.

In 2014, a systematic review by Davis Giardina et al. reported on the effect of providing patient access to their medical records (either paper or electronic) on measures of safety, effectiveness, patient-centredness, timeliness, efficiency, and equity [64]. Their review identified 27 English-language controlled studies, 19 of which were related to measures of effectiveness, 16 on patient-centredness, and two on efficiency. The authors reported that the outcomes were equivocal in relation to aspects of effectiveness and patient-centredness, and mixed in terms of efficiency. There was evidence that access to health records led to increased patient perceptions of control and some (mixed) evidence of reduced patient anxiety.

More recently, a large systematic interpretive review identified and assessed 143 published studies, 17 experimental in construct, about giving patients online access to their records [62]. This review found no studies which showed changes in patient outcomes. A few studies showed correction of medication errors and of uptake of preventive services, and patients welcomed particularly openness and understanding. In $13 \%$ of the studies, health professionals reported increased workload through online contacts but there were no increases in telephone or face-to-face activities. There were concerns about privacy and security, and the conclusion was that more advantaged patients gained most.

Most current evaluation studies have focussed on the immediate and somewhat mechanistic access to the current record, held electronically, within current philosophies of a professional-client service relationship. Something of a paradigm shift is needed to move to how the new, technology-supported, patient-centric coordinated care is organized with the citizen central and by no means subordinate [65]. Here evaluation needs to be one of communication as an aid to co-production, requiring very different constructs and measures. Then there is the further complication and barrier, that even modern services are too frequently designed by educated professionals and policy makers for 'People Like Us', and thus still fail to serve the disadvantaged and societally disconnected, even though they are known to have greater health needs [66].

\section{The Underlying Need for System Change}

The first examples of patient access to electronic records were simply a new window opened to the patient. They gave easy access - with controls - to the patient record, in a way that had been more difficult with a paper record. However, the full value of patient portals is in enabling the move to greater patient-professional parity and partnership, and co-production of health by the patient and as appropriate by his/ her informal carers. A more developed type of patient portal, operating within re-engineered services with greater equity, enables interaction with patients and contribution from them. Indeed, patient portals may be better considered as part of a social change programme. As such they do not constitute a singular intervention, but are made up of a complex set of interactions between people [67]. Expressed like this, eHealth in the form of patient portals contributes to the process of "creative destruction" [68], leading to transformations in existing relationships, care management, and even professional roles and responsibilities [69]. 


\section{Evaluation of Consumer Health Portals - The Need for a Theoretical Basis}

As described in the above section, many of the existing evaluation studies of consumer health or patient portals report mixed effects $[36,63]$. Systematic reviews conclude that evidence of consumer health portals on improved health outcomes, costs, or utilisation is insufficient $[36,64]$. Furthermore, none of the studies provide an understanding of whether all or part of the functionalities of the portal worked or not, why and how it worked or failed, and what was the contribution to care coordination. Patients in general have a positive attitude but more widespread use and research is needed to identify and solve ethnic and literacy barriers [36]. There are numerous perspectives and variables that evaluations of consumer portals need to consider such as: What is the defined goal of the portal? What do patients/consumers want? What constitutes success for each stakeholder? Patient satisfaction may be very different from care provider or government satisfaction.

\section{What Works for whom, in what Circumstances?}

With reference to existing evidence reviews, Otte-Trojel et al. expressed concern that there was a lack of appreciation about how patient portals contribute to better patient care or why some patient portals work and others do not [70]. The authors asserted that patient portals are complex and dynamic interventions which usually need to be adapted to meet the demands of their users. The authors undertook a realist review of diverse study designs to investigate complex interventions in specific contexts with the aim of identifying the mechanisms by which patient access may impact on clinical outcomes and health service delivery. They included 32 articles in their review and identified the following key mechanisms by which electronic patient portals may be expected to work:
- patient insight into information;
- activation of information;
- continuity of care;
- patient convenience.

The authors also noted that the evidence about patient portals tends to come from large health service providers where the portal is often a complement to an already existing (successful) disease management program. In such situations, it is often difficult to assign success to one single cause. They suggested that the impact of patient portals may be greater in more fragmented scenarios, which paradoxically are also the places where they are most difficult to implement [70]. Their point echoed the comments about inequalities in portal accessibility from Goldzweig et al.'s systematic review (reported above) [69].

\section{Participant Viewpoints}

The roles of participants are also likely to influence their views on what works satisfactorily. Arguably, there may be a "carer norm" to take into account for "informal" (unpaid) family helpers and a "sick person" norm to consider for patients struggling emotionally, physically, and logistically with the suffering, pain, fear, and the frustrations of their conditions. However, these could easily be over-simplistically compartmentalised. Currently, theory-based outcome measures and validated instruments are rare in the whole field of health informatics [71].

\section{Understanding Mechanisms}

To implement health portals successfully in the future, we need to know the factors that may lead to successful uptake and implementation [72]. This requires methods other than randomized clinical trials (RCTs) and meta-analyses of RCTs. One approach is performing a realist review. Such a review provides explanatory analysis of published literature and grey literature to discern what works for who, in what circumstances, in what respect and how [73, 74]. Central in the realist review is the generative model of causality that holds that, to infer a causal outcome $(\mathrm{O})$ between two events (cause $\mathrm{X}$ and effect $Y$ ), one needs to understand the underlying mechanism $(\mathrm{M})$ that connects them and the context $(C)$ in which that relation occurs. As depicted above, a realist review on how outcomes are achieved through consumer health portals reported four different mechanisms to yield the reported outcome improvements [69]. These mechanisms illustrate what works for specific outcomes, but not how and why they work. We still need to understand how these properties of a health information system are used and why in a specific context in order to inform decisions to be made concerning that system [75].

\section{Understanding Context}

Next to the mechanisms, the context or the social system where technology is implemented is important when evaluating consumer health portals. There is not a well-established definition of elements that constitute a (historical, physical and social) context of an intervention. A dictionary definition of context is "the circumstances, conditions, or objects by which one is surrounded" [76]. The GEP-HI guideline lists as contextual elements the organization (unit/ department, and the type of care provider and health system), and the user types that will be involved in the evaluation study as contextual elements [75]. Health technology assessment (HTA) methodology [77] goes further in the definition of various domains, topics, and issues for HTA. Of these, all but the technology description and actual outcome domains can be viewed as contextual elements. Within these, especially the health problem and current use, organisational, social, legal, and ethical aspects form important aspects of the context of use [76, 78]. The HTA organisational aspects include structural elements of the health care system, management issues related to technology, and technology impacts on health delivery process. Social aspects include definition and impacts of technology on patients and their life areas. Otte-Trojel identified that the context/setting in the literature found was quite consistent, in that context-mechanism-outcome patterns could not be identified: the 
portals were targeted at chronic disease patients, mainly in USA, with integrated health service networks, academic hospitals, and multi-speciality group practices [70].

When searching for the mechanisms that are behind the success of a technology intervention, there is a need to look at all the concurrent factors in the whole sociotechnical system, which may contribute to the success or failure of technology - or even be a prerequisite for it. In the case of consumer health portals, there is an added complexity of distributed use in two collaborating sociotechnical systems - that of the citizen or patient in the home environment and that of the carers in the hospital or clinic. In both of these, interlinked change between people and their behaviour, technology, and the environment accounts for the success or failure of a technology intervention [79].

\section{Understanding Organisational and Cultural Shifts}

E-Health systems do not work merely because they are constructed to do so, nor do they work in isolation. Their use and value is contingent upon many complex factors, including the context and setting in which they are introduced [80]. The capacity of eHealth to efficiently connect people, places, and organisations, and thus coordinate and optimise care in ways that have not been previously possible, has led to dramatic changes in the way patient care is performed [68]. Yet, understanding the mechanisms by which eHealth technologies like patient portals help to drive change can be difficult and challenging [69] .

\section{Models of the Theoretical Basis}

Understanding features and functions of the technology, and their context of use, helps us understand what works and how. Often hidden in the intervention, mechanisms can be explained by a more general scientific theory. A scientific theory is an explanation or a model based on observation, experimentation, and reasoning, especially one that has been tested and confirmed as a general principle helping to explain and predict natural phenomena.
Activity theory [81] offers three mechanisms between cause and effect from concrete to abstract: 1) the "what" mechanism - the characteristics of the physical artefacts (e.g. functionalities of the consumer health portal) that are used to cause the effect; 2) the "how" mechanism - the way they are used (e.g. patterns of use in the context); and 3) the "why" mechanism - exploring explanatory concepts and models for the use and impacts.

The four mechanisms identified by Otte-Trojel [70] seem to focus on the "what" level. The policy aims of governments, payers, and consumers of patient portals form one part of the "why" mechanism. These vary widely from coordination to patient empowerment, to reduced care costs, and improved data quality. However, it is not always clear what scientific model or theory has been used to support these policy aims [82]. The core theoretical concept behind patient portals is self-efficacy: "Confidence in one's ability to take action and overcome barriers" [83]. Evaluation studies based on a scientific theory are powerful as the underlying theory can be used to make predictions about alternative mechanisms that have not yet been observed. One example of a scientific theory that may form a basis for successful consumer portals or guide perceptive evaluation studies is the theory of planned behaviour (TPB) $[84,85]$.

A potential problem with evaluation frameworks is that they can become static, devised to measure things as they "once were", rather than dynamically as they "are becoming". This can lead to series of confounders or measurement biases which can lead to the adoption of inappropriate indicators, which inadequately measure the inputs and outputs of the eHealth innovation [68]. This point is addressed in the systematic review by Goldzweig et al. which noted the absence of reporting on organizational and provider context, and implementation processes for the patient portal [64]. The authors suggested that this made it difficult to distinguish between failure of the intervention and failure of the implementation in studies reporting no effect [64].

\section{The Theory of Planned Behaviour (TPB)}

TPB asserts that the main predictors of intention, and therefore behaviour, are the internal influence of attitude towards a given behaviour and the external influences of subjective norms and perceived behavioural control in the given situation - see Figure 1.

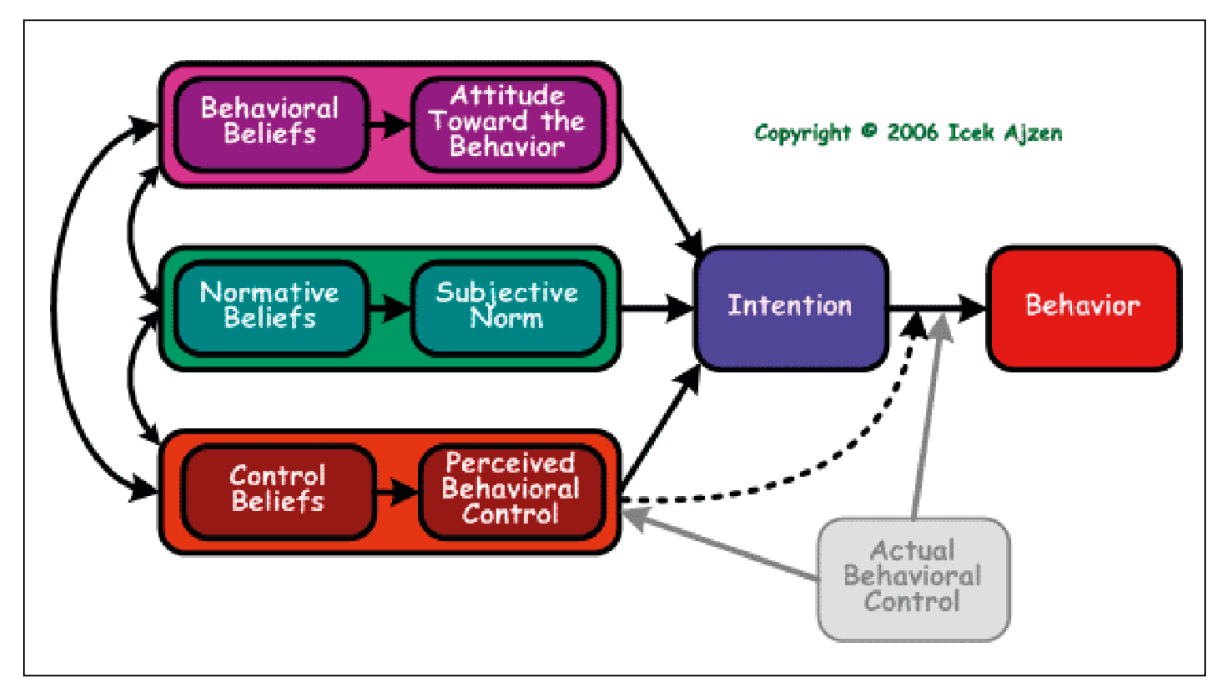

Fig. 1 Theory of Planned Behaviour (Aizen, 2006 [86]) 
TPB has been widely employed in health promotion programmes [82], and is particularly relevant to consumer health portals given the central importance of "perceived behavioural control", which is synonymous with self-efficacy - the implicit core justification for patient self-management [82]. TPB has been systematically reviewed and found to be the most commonly employed social-cognitive theory in interventions to predict healthcare practitioners' intentions and behaviours [84]. The systematic review concluded that TPB has been empirically demonstrated to be an effective predictor of behavioural intention (accounting for a weighted mean of $59 \%$ of variance in 56 studies), and, to a lesser extent, of actual behaviour (accounting for a weighted mean of $35 \%$ of variance in 14 studies). An alternative theoretical model, the theory of interpersonal behaviour [87], was even more effective as a predictor of intention, though from a smaller sample (accounting for a weighted mean of $81 \%$ of variance in three studies). TPB has been extended by some researchers to include a specific healthcare dimension of the "professional norm" [88], which is related to the effect of normative professional influences on the individual practitioner.

\section{Example of Evaluation of Mechanisms in eHealth Monitoring Activities}

Currently, in the Nordic countries, nation-wide surveys identify uptake and use of eHealth such as clinicians' access to a nation-wide up-to-date list of medications prescribed electronically to patients, availability of patient portals, as well as the countries implementation mechanisms. Both "what" mechanisms, i.e. implementation of actual functionalities of the national technologies, and "how" mechanisms (contextual elements of use), are included in the surveys. The why mechanisms are analysed via the analysis of goals set for the functionalities in the national eHealth policies, but not what scientific models or theories are reflected in these policy aims. Based on the nation-wide surveys and policy analysis, within the coming years identifying some context-mechanism-outcome patterns will be possible. Figure 2 shows preliminary results over a three-year period of the nation-wide service offered to clinicians to view medications prescribed to the patient. Denmark shows the fastest and highest uptake.

Figure 3 shows the variation in policy goals in the Nordic countries. Variations due to contextual differences (e.g. of primary and specialised care contexts) are visible in publications of national surveys e.g. [89]. The policy analysis shows that Denmark, Sweden, and Norway have focused more on clinical infrastructure, and Finland on technical infrastructure. A more rapid implemen- tation of the ePrescribing system is visible in Denmark where a nationwide viewing of medication prescribed is available. Policy goals thus seem to act as one mechanism between technology and its diffusion. A much longer follow-up-period, and a much more detailed analysis of the "what" and "why" mechanisms from each country in the context would be needed in order to connect the features and functionalities of technology in specific contexts to specific outcomes such as reduction of duplicate prescribing or medication errors.

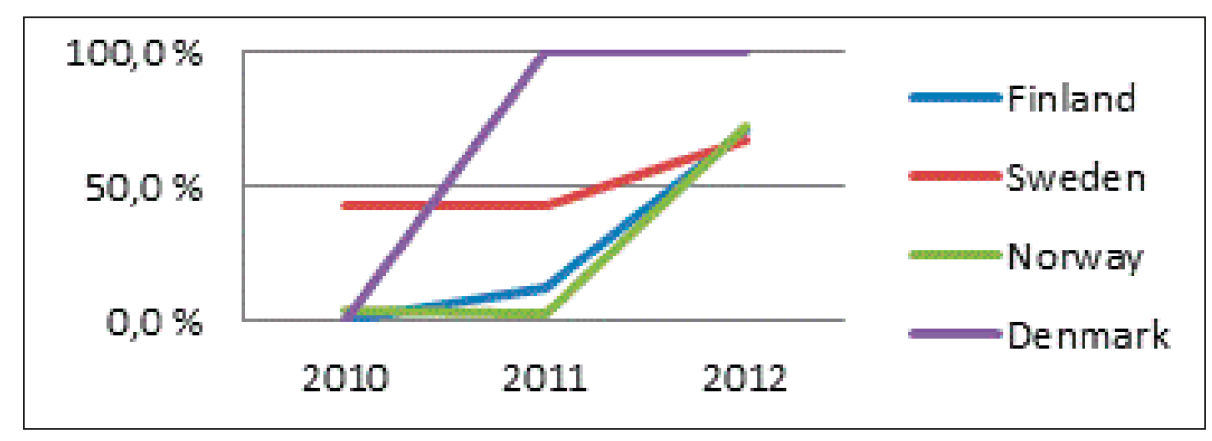

Fig. 2 Proportion of public ambulatory care organisations offering access to nation-wide medications prescribed electronically to patients in Nordic Countries in 2010-2012

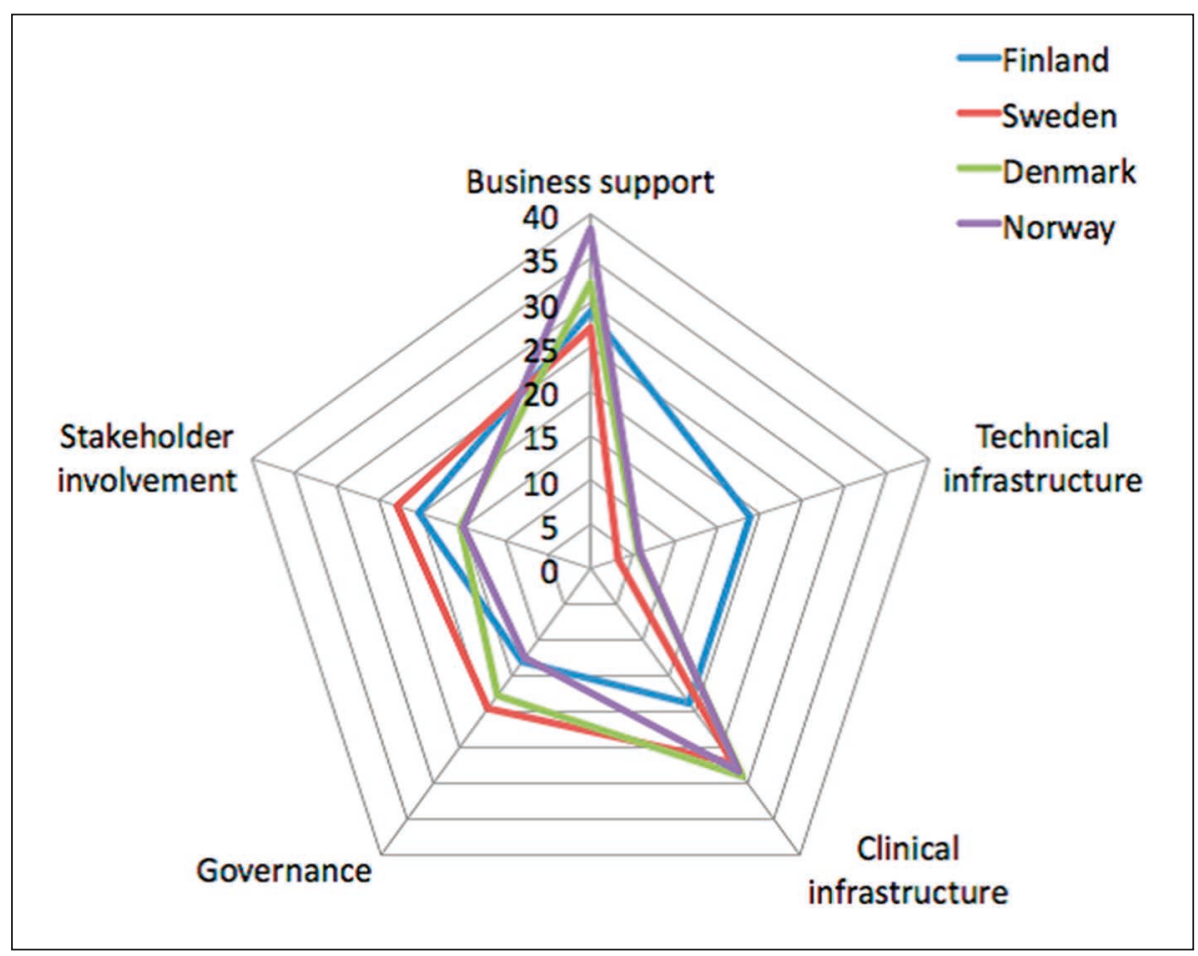

Fig. 3 Strategic focus profiles (concept frequency) in the eHealth policy documents in Nordic Countries 


\section{Conclusion - The Need for Underpinning Theory}

Consumer health portals should be developed and evaluated with the understanding of their contexts of use, and based on a theoretical framework such as, for example, the theory of planned behaviour, by which the functions of the portal can perceive the behaviour control to be influenced, as a means of optimising and coordinating care. Evaluation studies which are based on such a scientific theory, and that compare variants of theoretical mechanisms (e.g. providing personalised information versus general patient information), and different contexts (e.g. patient portals used by young, well educated patients such as in vitro fertilisation clinics versus the same patient portals used by elderly patients with dementia) will provide knowledge on what works for who, in what circumstances, in what respect and how. It has been reported [70] that most of the studies did not describe in detail the mechanisms believed to be in play. Careful reading of the text was required to identify the (what) mechanisms proposed to link the consumer health portal to an outcome. How the processes were re-engineered to take full advantage of the technology (how mechanism) and what norms, goal and theories were behind the change (why mechanisms) were not searched for or reported at all. Hence, future evaluation studies on health consumer portals need to report explicitly on underlying theories, mechanisms evaluated, and the context in which the evaluation study takes place.

\section{Legal Aspects}

The legal aspects of patient portals, and indeed, of controlled data sharing, have been less explored, the assumption being that pre-existing record keeping and accountability mechanisms flowed through the new linkages. In many countries, there are laws that govern medical record keeping and the protection of the privacy of the patients whose data are documented in those records. These laws list the responsibilities of care providers and their institutions in this respect. However, in future this will need more consideration, especially when codification becomes more detailed and specific.

For example in the US, the Health Insurance Portability and Accountability Act (HIPAA) applies for what are called the covered entities (see http://www.hhs.gov/ ocr/privacy/hipaa/understanding/coveredentities/), which include health care providers, health plans, and health care clearinghouses. Their business associates need also to be HIPAA compliant. When a health organisation offers a PHR, HIPAA applies, but there are examples where the legal situation is less clear. In a recent case, a health care provider encouraged the use of a PHR service provided by a third party. Data from the health care provider could be uploaded to that PHR, and the patient had to sign a contract with that third party. Since this PHR provider is not a "covered entity", HIPAA does not apply, and the service provider had to explicitly state that when a patient entered data into that system, the service provider owned that data and was allowed to make any commercial benefit of that data. In summary, some PHR services are offered with the same privacy protection as health data maintained by covered entities, but other PHR services provide less protection.

\section{Discussion - The Challenges Ahead}

Person-Centric Care and Care Coordination are each radical and exciting concepts which are appropriate - indeed overdue - in the modern world of educated societies where an information-rich environment with a high degree of digitisation and broadband communication is available in most service sectors. Yet, that is not the case in the health and care domain, not just because of complexities and of confidentiality issues, but because such new approaches are disturbingly challenging for many mature health and care professionals, who commenced practice in a very different era, and who are secure only in their current processes. But the purpose is not just to make change, which itself has no value but a significant cost associated with disturbance of settled patterns. The purpose must be to achieve in health and healthcare greater equity, better satisfaction, better health outcomes, and greater efficiency, both intrinsically, but also through greater co-production by patients and by civil society harnessing social capital, for which care coordination is a key means. Patient portals, in their most interactive forms, are potentially a key part of this significant transition. In turn, that leads to the need for an evaluation continuum:

- Patient portals - do they work at the display and transaction level?

- Patient portals - do they change understanding and improve power balance?

- How best to improve care coordination [11]?

- How best to achieve equity and satisfaction in health including patient access to their own information?

The existence of patient portals is beginning to spread across many countries. This is despite the seemingly inconsistent research evidence about how these technologies impact on patient care $[36,90]$. Research findings continue to show that although people want to be informed and involved in decisions about their medical care [91], shared decision-making and patient-centred care are not currently practiced very widely. [29]

Patient information needs are not limited to general knowledge. They also include access to the content of medical records. Allowing patients to access personalized health information opens up the potential to improve communication between family members, and between patients and providers. It can also help patients to prepare for clinical visits and to cope with the potential anxiety related to the clinical visit [27]. Enabling patient access to information is also associated with the provision of decision aids to patients. Stacey et al. carried out a Cochrane Review of 115 randomized controlled trials [92], which showed that the availability and utilisation of decision aids (compared to their non-use) led to patients having:

- Enhanced knowledge and understanding of the harms and benefits of various options

- Better perceptions of risk 
- Greater comfort with decisions

- Decisions aligned with patient goals and preferences

Currently, the evidence would suggest that steady steps are being made along this road, but there is much ground to be covered. Then, just as important, is ensuring that this evidence influences policy appropriately [93], as this is important both for informatics development and investment, but more fundamentally for health and care policy. And a major source of reliable scientific evidence is properly structured evaluation.

\section{Conclusion}

Person-centric Care and Care Coordination are fundamental meaning of life, and purpose of health and care system issues. Patient portals, emulating consumer access and control in commerce within the strong necessary parameters of providing organisations, would seem to be an important means towards this end; they should be seen as empowering and assistive for those comfortable with them, though not compulsory for those less confident. These issues and technologies are immensely challenging, yet vitally important. It is necessary for society to raise them openly, including the pivotal enabling role that health informatics has to play, and the related required controls and assurances, together with evaluation-based evidence, to assess the integrity and effectiveness of its input. There will be challenges and disappointments, both in finding and applying sound evaluation processes, and in interpreting and using the evidence to question the status quo and to assess progress. But the transformation has started, patient portals are a clear demonstration of this sea change, and the next step is to capture and use the knowledge on what is most effective, with an understanding of how and why.

\section{Acknowledgement}

The authors acknowledge Jan Talmon, School for Public Health and Primary Care (Caphri), Maastricht University, The Netherlands, for his wise advice given freely during the preparation of this material.

\section{References}

1. De Silva D. Helping measure person-centred care. A review of evidence about commonly used approaches and tools used to help measure person-centred care. The Health Foundation. Evidence Review; March 2014. Available at http:// www.health.org.uk/public/cms/75/76/313/4697/ Helping\%20measure\%20person-centred\%20 care.pdf?realName $=$ Lnl7Fn.pdf (accessed 19 December 2014).

2. Health Foundation. Person-centred Care Made Simple - what everyone should know about person centred care. London: Health Foundation; October 2014. Available at http://www.health.org.uk/ public/cms/75/76/313/5061/Person-centred $\% 20$ care $\% 20$ made $\% 20$ simple.pdf?realName $=\mathrm{d}$ vORCq.pdf (Accessed 19 December 2014).

3. Kodner DL. All together now: a conceptual exploration of integrated care. Healthc Q 2009 Oct;13 Spec No:6-15.

4. Kodner DL, Spreeuwenberg C. Integrated care: meaning, logic, applications, and implications-a discussion paper. Int J Integr Care 2002;2:e12. Available from: URN:NBN:NL:UI:10-1-100309 (accessed 9 December 2014).

5. Goodwin N. Understanding Integrated Care: a complex process, a fundamental principle. Int J Integr Care 2013;13:e011. Available from: URN:NBN:NL:UI:10-1-114416.

6. Finset A. Research on person-centred clinical care. J Eval Clin Pract 2011 Apr;17(2):384-6.

7. Olsson LE, Jakobsson Ung E, Swedberg K, Ekman I. Efficacy of person-centred care as an intervention in controlled trials - a systematic review. J Clin Nurs 2013 Feb;22(3-4):456-65.

8. Hippocrates The Art; Greece, c2500 BC.

9. Tsiompanou E, Marketos SG. Hippocrates: timeless still. J R Soc Med 2013;106,288-92.

10. Rigby M. The Core Vision of Person-Centred Care in a Modern Information-Based Society. In: Meyer I, Müller S, Kubitschke L. Achieving Effective Integrated E-Care Beyond the Silos. Hershey PA: IGI Global; 2014; p. 1-21. ISBN: 978-1-4666-6138-7.

11. McDonald KM, Schultz E, Albin L, Pineda N, Lonhart J, Sundaram V, et al. Care Coordination Measures Atlas Update June 2014. U.S. Department of Health \& Human Services. Washington DC: Agency for Healthcare Research and Quality; 2014. Available at http://www.ahrq.gov/ professionals/prevention-chronic-care/improve/ coordination/atlas2014/index.html (accessed 19 December 2014).

12. Wagner EH. Care for chronic diseases. The efficacy of coordinated and patient centred care is established, but now is the time to test its effectiveness. BMJ Oct 26, 2002;325(7370): 913-4.

13. Chronic diseases and health promotion. WHO global report. http://www.who.int/chp/chronic_disease_report/part1/en/index4.html (accessed 19 December 2014).

14. Bodenheimer T, Wagner EH, Grumbach K. Improving primary care for patients with chronic illness. JAMA 2002;288:1775-9.

15. Weingarten SR, Henning JM, Badamgarav E,
Knight K, Hasselblad V, Gano A, et al. Interventions used in disease management programmes for patients with chronic illness-which ones work? Meta-analysis of published reports. BMJ 2002:325:925-8.

16. Conference Board of Canada. Valuing Time Saved. Assessing the Impact of Patient Time Saved from the Adoption of Consumer Health Solutions. The Conference Board of Canada; September 19, 2012.

17. Canada Health Infoway. The emerging benefits of electronic medical record use in community-based care. A study commissioned by Canada Health Infoway; April 2013.

18. Tornbjerg K, Bertelsen P. Undersøgelse af borgernes anvendelse af sundheds-it i 2013 - en udforskning af danskernes kendskab, holdninger og forhold til it, til gavn for eget helbred. Dansk Center for Sundhedsinformatik, DaCHI. Aalborg University; March 2014. Available from http://www. dachi.aau.dk/digitalAssets/85/85883_14_2_undersoegelse_af_borgernes_anvendelse_af_sundheds-it_i_2013.pdf(accessed 19 December 2014)

19. Hyppönen, H, Hyry, J, Valta, K, Kyrki, A. Sosiaali- ja terveydenhuollon sähköinen asiointi - kansalaisten kokemukset ja tarpeet. [Electronic services for citizens in Social and health care - use, experiences and needs].Report x/2014. Helsinke, Finland: National Institute for Health and Welfare. (in press)

20. Cooper AF. Whose illness is it anyway? Why patient perceptions matter. Int $\mathrm{J}$ Clin Pract 1998;52(8):551-6.

21. Nettleton S, Hanlon G. 'Pathways to the Doctor' in the Information Age: the Role of ICTs. In: Webster A. Contemporary Lay Referral Systems. New Technologies in Health Care Challenge, Change and Innovation. Hampshire: Palgrave Macmillan; 2006. p. 57-70.

22. Department of Health. The expert patient: a new approach to chronic disease management in the 21 st century. London: Stationery Office; 2001.

23. http://www.nhs.uk/NHSEngland/AboutNHSservices/doctors/Pages/expert-patients-programme. aspx (accessed 19 December 2014).

24. http://www.selfmanagementuk.org/services/ programmes (accessed 19 December 2014)

25. Chewning B, Bylund CL, Shah B, Arora NK, Gueguen JA, Makoul G. Patient preferences for shared decisions: a systematic review. Patient Educ Couns 2012;86(1):9-18.

26. Murphy DR, Singh H, Berlin L. Communication breakdowns and diagnostic errors: a radiology perspective. Diagnosis 2014;1(4):253-61.

27. Arnold CW, McNamara M, El-Saden S, Chen S, Taira RK, Bui AAT. Imaging informatics for consumer health: towards a radiology patient portal. J Am Med Inform Assoc 2013;20(6):1028-36.

28. Stevenson FA, Cox K, Britten N, DundarY. A systematic review of the research on communication between patients and health care professionals about medicines: the consequences for concordance. Health Expect 2014;7(3):235-45.

29. Alston C, Berger ZD, Brownlee S, Elwyn G, Fowler FJ Jr., LK Hall, et al. Shared Decision Making Strategies for Best Care: Patient Decision Aids. 2014

30. Blobel B. Onconet: a secure infrastructure to 
improve cancer patients' care. Eur J Med Res 2000 Aug 18;5(8):360-8.

31. Baldry M, Cheal C, Fisher B, Gillett M, Huet V. Giving patients their own records in general practice: experience of patients and staff. Br Med J 1986 Mar 1;292(6520):596-8.

32. Honeyman A, Cox B, Fisher B. Potential impacts of patient access to their electronic care records. Inform Prim Care 2005;13(1):55-60.

33. Fisher B, Fitton R, Poirier C, Stables D. Patient record access--the time has come. Stud Health Technol Inform 2006;121:162-7.

34. Fisher B, Fitton R, Poirier C, Stables D. Patient record access--the time has come! Br J Gen Pract 2007 Jun;57(539):507-11.

35. http://www.paers.net/index.shtml (accessed 19 December 2014)

36. Ammenwerth E, Schnell-Inderst P, Hoerbst A. The Impact of Electronic Patient Portals on Patient Care: A Systematic Review of Controlled Trials. J Med Internet Res 2012;14(6):e162. doi:10.2196/ jmir.2238].

37. Bourgeois FC, Mandl KD, Shaw D, Flemming D, Nigrin DJ. Mychildren's: integration of a personally controlled health record with a tethered patient portal for a pediatric and adolescent population. AMIA Annu Symp Proc 2009;2009:65-69.

38. Institute of Medicine. Crossing the Quality Chasm: A New Health System for the 21st Century. Washington: National Academy Press; 2001.

39. Giardina TD, Singh H., Should patients get direct access to their laboratory test results?: An answer with many questions. JAMA 2011;306(22):2502-3.

40. Feeley TW and Shine KI. Access to the medical record for patients and involved providers: transparency through electronic tools. Ann Intern Med 2011;155(12):853-4.

41. Day K, Bain C. Opening medical records for patients - A limited literature review. PULSE IT 2014;40-3.

42. McDonald KM, Bryce CL, Graber ML. The patient is in: patient involvement strategies for diagnostic error mitigation. BMJ Quality \& Safety 2013;22 (Suppl 2):ii33-ii39.

43. Markle Foundation. Connecting for Health - A Public-Private Collaborative. 2003. The Personal Health Working Group - Final Report. Available from http://www.providersedge.com/ehdocs/ ehr_articles/The_Personal_Health_Working_Group_Final_Report.pdf [accessed 19 November 2014]

44. Kaelber DC, Jha AK, Johnston D, Middleton B, Bates DW. A research agenda for personal health records (PHRs). J Am Med Inform Assoc 2008 Dec;15(6):729-36.

45. Microsoft Health Vault URL: https://www.healthvault.com/au/en. (accessed 19 December 2014).

46. Apple Health URL: https://www.apple.com/au/ios/ whats-new/health/. (accessed 19 December 2014)

47. Weingart SN, Rind D, Tofias Z, Sands DZ. Who uses the patient internet portal? The PatientSite experience. J Am Med Inform Assoc 2006 JanFeb;13(1):91-5.

48. Kaiser Permanente Annual Report 2013. http:/ share.kaiserpermanente.org/static/kp_annualreport_2013/?kp_shortcut_referrer=kp.org/annualreport\#executive-letter (accessed 9 December 2014).

49. https://www.sundhed.dk/service/english/about- the-ehealth-portal/background/ (accessed 10 December 2014).

50. Peterson ME. Patients access to their health data on the Danish national e-health portal. http://www.ehfg.org/fileadmin/ehfg/Website/ Archiv/2011/Presentations/W8/W8-Petersen.pdf

51. Greenhalgh, T, Stramer K, Bratan T, Byrne E, Russell J, Hinder S, et al. The Devil's in the Detail: Final report of the independent evaluation of the Summary Care Record and Health Space programmes. London: University College London; 2010.

52. http://www.ehealth.gov.au (accessed 20 December 2014).

53. Dearne K. An analysis of Commonwealth Government annual reports covering e-health and PCEHR activities in 2013-14. Consumers e-Health Alliance; http://ceha.org.au/wp-content/ uploads/2014/12/AnalysisPCEHR-Final.pdf (accessed 20 December 2014).

54. Greenhalgh T, Hinder S, Stramer K, Bratan T, Russell J. Adoption, non-adoption, and abandonment of a personal electronic health record: case study of HealthSpace. BMJ 2010 Dec 20;341:c7219.

55. Patient Online, NHS England, 2014. http://www. england.nhs.uk/ourwork/pe/patient-online/. (accessed 20 December 2014)

56. Hannan A. Providing patients online access to their primary care computerised medical records: a case study of sharing and caring. Inform Prim Care 2010,18:41-9.

57. Barbarito F, Pinciroli F, Barone A, Pizzo F, Ranza R, Mason J, et al. Implementing the lifelong personal health record in a regionalised health information system: The case of Lombardy, Italy. Comput Biol Med 2013 Nov 4. pii: S0010-4825(13)00308-9. doi: 10.1016/j.compbiomed.2013.10.021. [Epub ahead of print].

58. Hyppönen H. Sosiaali- ja terveydenhhollon sähköinen asiointi. Kansalaisten kokemukset ja tarpeet. [Electronic services in the social welfare and health care sector - experiences and needs of people with chronic illnesses] (in Finnish). Finnish Journal of eHealth and eWelfare (FinJeHeW) 2015;7(2-3): 88-1033.

59. Phelps RG, Taylor J, Simpson K, Samuel J, Turner AN. Patients' Continuing Use of an Online Health Record: A Quantitative Evaluation of 14,000 Patient Years of Access Data. J Med Internet Res 2014;16(10):e241.

60. Mukoro, F. Renal Patient View: A system which provides patients online access to their test results. Final evaluation report. NHS Kidney Care; 2012.

61. Yamin CK, Emani S, Williams DH, Lipsitz SR, Karson AS, Wald JS, et al. The digital divide in adoption and use of a personal health record. Arch Intern Med 2011 Mar 28;171(6):568-74.

62. de Lusignan S, Ross P, Shifrin M, Hercigonja-Szekeres M, Seroussi B. A comparison of approaches to providing patients access to summary care records across old and new Europe: an exploration of facilitators and barriers to implementation. Stud Health Technol Inform 2013;192:397-401.

63. Goldzweig CL, Orshansky G. Paige NM, Towfigh AA, Haggstrom DA, Miake-Lye I, et al. Electronic patient portals: evidence on health outcomes, satisfaction, efficiency, and attitudes: a systematic review. Ann Intern Med 2013;159(10):677-87.

64. Davis Giardina T, Menon S, Parrish DE, Sittig DF, Singh H. Patient access to medical records nd healthcare outcomes: a systematic review. J Am Med Inform Assoc 2014;21:737-41.

65. Rigby M, Koch S, Keeling D, Hill P. Developing a New Understanding of Enabling Health and Wellbeing in Europe - Harmonising Health and Social Care Delivery and Informatics Support to Ensure Holistic Care; European Science Foundation, Strasbourg; 2013. available on http://www.esf. org/fileadmin/Public_documents/Publications/ Health_Wellbeing_Europe.pdf.

66. Showell C, Turner P. The PLU problem: are we designing personal ehealth for people like us? Stud Health Technol Inform 2013;183:276-80.

67. Clarke A. Evidence-Based Evaluation in Different Professional Domains: Similarities, Differences and Challenges. In: Shaw IF, Greene JC, Mark MM, editors. Handbook of Evaluation: Policies, Programs and Practices. London: Sage; 2006. p. 559-81.

68. Organisation for Economic Co-operation Development. OECD Guide to Measuring the Information Society 2011: OECD; Paris; 2011.

69. Menou MJ, Taylor RD. A "Grand Challenge": Measuring Information Societies. The Inform Soc 2006;22(5):261-7.

70. Otte-Trojel T, de Bont A, Rundall TG, van de Klundert J. How outcomes are achieved through patient portals: a realist review.J Am Med Inform Assoc 2014 Jul-Aug;21(4):751-7.

71. Scott PJ, Brown A, Friedman C, Wyatt J, Georgiou A, Eisenstein E. Improving the Science of Health Informatics by using Validated Instruments and Outcome Measures. Workshop presented at Medical Informatics Europe 2014, Istanbul.

72. Hyppönen H. eHealth services and technology: challenges for co-development. Human technology 2007;3(2):188-213.

73. Pawson R. Evidence-Based Policy. A Realist Perspective. Sage; 1996.

74. Wong G, Greenhalgh T, Westhorp G, Pawson R. RAMESES publication standards: realist syntheses. BMC Med 2013;11:21.

75. Nykänen P, Brender J, Talmon J, de Keizer N, Rigby M, Beuscart-Zephir M-C, et al. Guideline for good evaluation practice in health informatics (GEP-HI). Int J Med Inform 2011;815-27.

76. http://www.merriam-webster.com/thesaurus/ context? show $=0 \& t=1416901024$

77. EUnetHTA Joint Action 2, Work Package 8. HTA Core Model ${ }^{\circledR}$ version 2.1 PUBLIC DRAFT 23 (Pdf); 2014. Available from http://www.corehta. info/BrowseModel.aspx.

78. Hyppönen H, Viitanen J, Reponen J, Doupi P, Jormanainen V, Lääveri T, et al. Large-scale eHealth Systems: Providing Information to Support Evidence-based Management. eTELEMED 2011: The Third International Conference on eHealth, Telemedicine, and Social Medicine. IARIA, 2011.

79. Hyppönen H. eHealth Services and Technology : Challenges for Co-Development. Human Technology 2007;(2):188-213.

80. Leonardi P, Barley S. Materiality and change: Challenges to building better theory about technology and organizing; Information and 
Organization 2008;18(3):159-76.

81. Engeström Y, Reijo Miettinen R, Punamäki R-L (Editors). Perspectives on Activity Theory (Learning in Doing: Social, Cognitive and Computational Perspectives). Cambridge, UK: University Press; 1999.

82. Bodenheimer T, Lorig K, Holman H, Grumbach K. Patient self-management of chronic disease in primary care. JAMA 2002 Nov 20;288(19):2469-75.

83. Rimer B, Glanz K. Theory at a glance.. Washington DC: National Cancer Institute; 2005.

84. Godin G, Belanger-Gravel A, Eccles M, Grimshaw J. Healthcare professionals' intentions and behaviours: a systematic review of studies based on social cognitive theories. Implement Sci 2008;3: 36 .

85. Al-Lozi E, Papazafeiropoulou A. Intention-Based Models: The Theory of Planned Behavior Within the Context of IS. In: Dwivedi YK, Wade MR, Schneberger SL, editors. Information Systems Theory, Vol. 29. New York: Springer; 2012.p. 219-39.
86. Ajzen I. TPB Diagram.; 2006. Retrieved 11 December, 2014, from http://people.umass.edu/ aizen/tpb.diag.html

87. Triandis H. Values, attitudes, and interpersonal behavior. In: Page M, Lincoln N, editors. Nebraska Symposium on Motivation, Vol. 27. University of Nebraska Press; 1980. p. 195-259.

88. Daneault S, Beaudry M, Godin G. Psychosocial determinants of the intention of nurses and dietitians to recommend breastfeeding. Can J Public Health 2004;95(2):151-4.

89. Viitanen J, Hyppönen H, Lääveri T, Vänskä J, Reponen J, Winblad I. National questionnaire study on clinical ICT systems proofs: physicians suffer from poor usability. Int J Med Inform 2011; 80(10):708-25.

90. de Lusignan S, Mold F, Sheikh A, Majeed A, Wyatt JC, Quinn T, et al. Patients' online access to their electronic health records and linked online services: a systematic interpretative review. BMJ Open 2014 Sep 8;4(9):e006021

91. Chewning B, Bylund CL, Shah B, Arora NK, Gueguen JA, Makoul G. Patient preferences for shared decisions: a systematic review. Patient Educ Couns 2012;86(1):9-18.

92. Stacey D, Bennett CL, Barry MJ, Col NF, Eden $\mathrm{KB}$, Holmes-Rovner M, et al. Decision aids for people facing health treatment or screening decisions. Cochrane Database Syst Rev 2011;10(10).

93. Rigby M, Ammenwerth E, Beuscart-Zephir M-C, Brender J, Hyppönen H, Melia Set al. Evidence Based Health Informatics: 10 Years of Efforts to Promote the Principle - Joint Contribution of IMIA WG EVAL and EFMI WG EVAL. Yearb Med Inform 2013;34-46.

\section{Correspondence to:}

Emeritus Professor Michael Rigby

Lavender Hill, 6 Carrighill Lower

Calverstown, Kilcullen

Co. Kildare, Ireland

Tel: + 35345485858

E-mail:m.j.rigby@keele.ac.uk 